\title{
Study on Rat Subcutaneous Reaction to Experimental Polyurethane Elastomers
}

\author{
Xing Yan WANG ${ }^{1}$, Atsuko BABA ${ }^{2}$, Kunihisa TANIGUCHI ${ }^{3}$, Maki HAGIO ${ }^{2}$ and Koji MIYAZAKI ${ }^{4}$ \\ ${ }^{1}$ Graduate School, Department of Dental Engineering, Fukuoka Dental College, 2-15-1 Tamura, Sawara-ku, Fukuoka 814-0193, \\ Japan \\ ${ }^{2}$ Department of Oral Growth \& Development, Fukuoka Dental College, 2-15-1 Tamura, Sawara-ku, Fukuoka 814-0193, Japan \\ ${ }^{3}$ Department of Morphological Biology, Fukuoka Dental College, 2-15-1 Tamura, Sawara-ku, Fukuoka 814-0193, Japan \\ ${ }^{4}$ Department of Dental Engineering, Fukuoka Dental College, 2-15-1 Tamura, Sawara-ku, Fukuoka 814-0193, Japan \\ Corresponding author, E-mail:wxingyjp@yahoo.co.jp
}

Received July 5, 2004/Accepted October 9, 2004

The purpose of the study was to investigate the biocompatibility of experimental elastomers, E580 and E590. The experimental elastomers and the control - a clinically used elastomer - were implanted into the subcutaneous tissue of rats. The tissue reactions were examined histologically on the $3 \mathrm{rd}, 7 \mathrm{th}, 14 \mathrm{th}, 28 \mathrm{th}$, and 56 th day after implantation. It was found that there were some irritant responses in the tissues adjacent to the implanted elastomers during the first week. However, the inflammatory tissue reaction subsided substantially from the second week onwards. The stable fibrous capsule surrounding the elastomer was formed after eight weeks. The tissue responses of the control, E580, and E590 were similar. The results suggested that the long-term tissue irritation of the experimental elastomers was so low such that they have the potential to be applied clinically.

Key words: Polyurethane elastomer, Rat subcutaneous implantation, Biocompatibility

\section{INTRODUCTION}

In a bid to develop fluoride-releasing elastomers so as to prevent enamel demineralization of orthodontic patients, Itoh ${ }^{1)}$ studied the properties of eight kinds of polyurethane elastomer. He found that the polyurethane elastomer, E580, had suitable mechanical properties to be used as an orthodontic module. Soon after, a new polyurethane elastomer E590 was developed by the same corporation. In view of their favorable mechanical properties, Wang ${ }^{2)}$ found that both E580 and E590 showed great potential to be used as the base elastomers of the fluoride-releasing modules.

However, when dental materials are to be developed for clinical application, biocompatibility issues such as tissue irritation or cytotoxicity must be addressed and investigated thoroughly. Although extensive studies on the biocompatibility of some other polyurethane elastomers have been $\operatorname{done}^{3-6)}$, there were no reports on the biocompatibility of E580 and E590. The objective of this study was to investigate the biocompatibility of E580 and E590 as base elastomers. To this end, the experimental elastomers were not incorporated into any fluoride compound. The materials were implanted into the subcutaneous tissue of rats for eight weeks, and the tissue reactions investigated by histological examination.

\section{MATERIALS AND METHODS}

\section{Specimens preparation}

The materials used in this study were namely two kinds of experimental polyurethane elastomer (E580 and E590, Nihon Miractoran, Osaka, Japan) and a clinically used separator elastomer (3M Unitek, USA) as control. Fifty disks (diameter: $4 \mathrm{~mm}$, thickness: $0.5 \mathrm{~mm}$ ) were prepared from each of the three elastomers respectively. The experimental polyurethane elastomers were composed of diphenylmethane diisocyanate and $\varepsilon$-caprolacton. Although the compositions of E580 and E590 were the same, cross-links in their structures were different. As for the control, its main structure was also that of the polyurethane elastomer. All the specimens were cleaned ultrasonically for 30 seconds and dried by air. Then they were sterilized by ethylene oxide gas just before implantation.

\section{Rat subcutaneous implantation}

Fifty male Wistar rats aged about 5 weeks' old were used in the study - in conformance to the procedures of the Animal Ethics Committee of Fukuoka Dental College. To help them adapt to the new environment, the rats were bred for three days before implantation was performed.

In preparation for implantation, the rats were anesthetized with sodium pentobarbital (Nembutal ${ }^{\mathrm{TM}}$ ) by dosages of $50 \mathrm{mg} / \mathrm{kg}$. After the back of the rat was shaved, three parallel incisions were made along the center line of the back skin at equal distances apart. The subcutaneous tissue was spread by blunt dissection. The three specimens - control, E580, and E590 - were randomly implanted into rat's three subcutaneous pockets. The wounds were then sutured with silk sutures. 
Fig. 1 shows the implanted disk-like specimen on the reverse side of rat skin. The rats were carefully cared for after the operation. Ten rats were humanely sacrificed on the 3rd, 7th, 14th, 28th, and 56 th day after implantation respectively. The implanted specimens and the associated skin and connective tissues were excised and immediately fixed in $10 \%$ neutral-buffered formalin. After dehydration, the tissue blocks were embedded in paraffin and sectioned at about $4-\mu \mathrm{m}$ thickness. The sections were stained with hematoxylin and eosin (H.E.) and observed with an optical microscope.

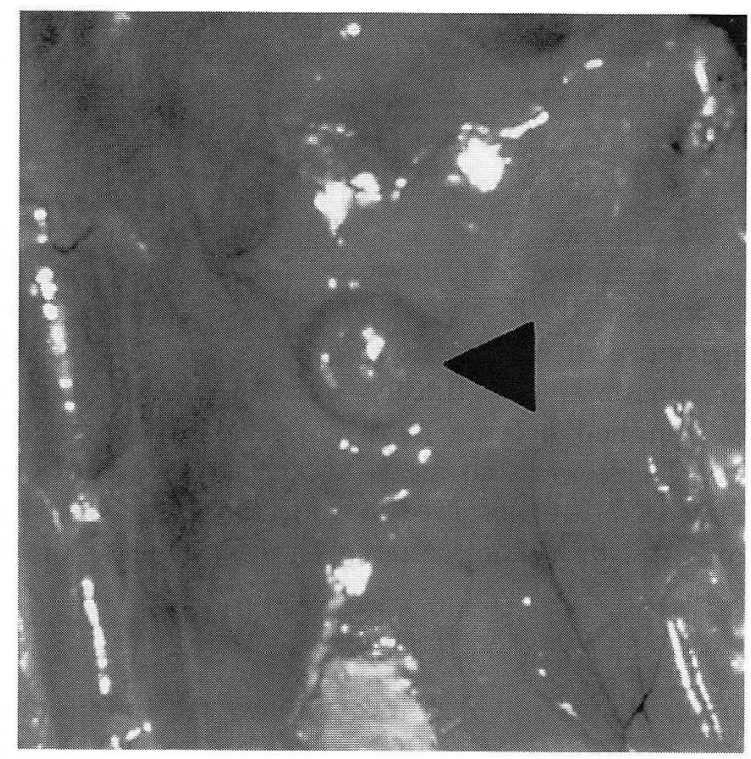

Fig. 1 Implanted specimen exhibited on the reverse side of the subcutaneous tissue of a rat.

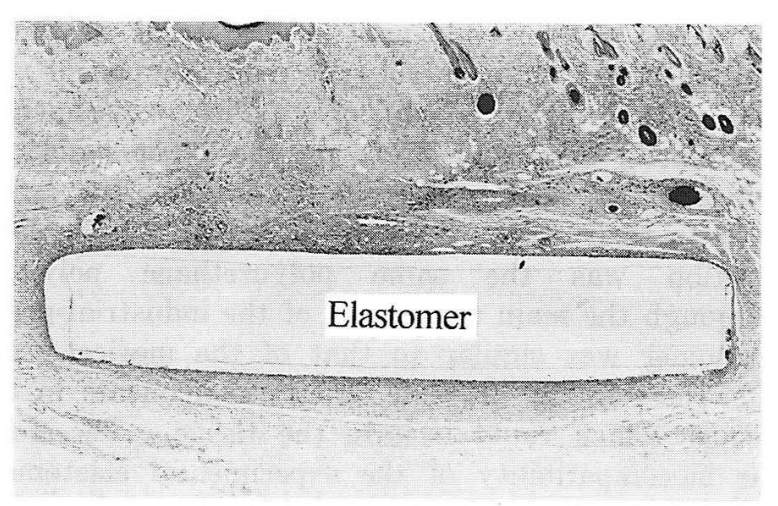

Fig. 2 Histological observation of the tissue response of specimen (E590) on the 7th day after implantation. Granulation tissue with inflammatory infiltration surrounding the specimen was completely shown (H.E. staining, $\times 6.6$ ).

\section{RESULTS}

On the 3rd day after implantation, the section wound was still not healed. Vascular dilatation and mild inflammatory infiltration (composing mainly of neutrophils) were observed near the specimen. In the connective tissue close to the wound, light fluid exudates were also found. The histological observations of the control, E580, and E590 were not significantly different.

On the 7th day, granulation tissue with vascular dilatation and inflammatory cell infiltration was formed adjacent to the specimen (Fig. 2). Enlarged blood vessels and congestions - accompanied with a mild inflammatory infiltration of lymphocytes and macrophages - were also observed (Fig. 3). The tissue reactions showed no significant differences among the control, E580, and E590.

On the 14th day, a layer of fibrous tissue surrounding the specimen was formed. It was mainly composed of fibrocytes and collagen fibers. However, a few proliferating capillaries and lymphocytes were scattered in the fibrous tissue adjacent to the specimen. There were no significantly different tissue re-
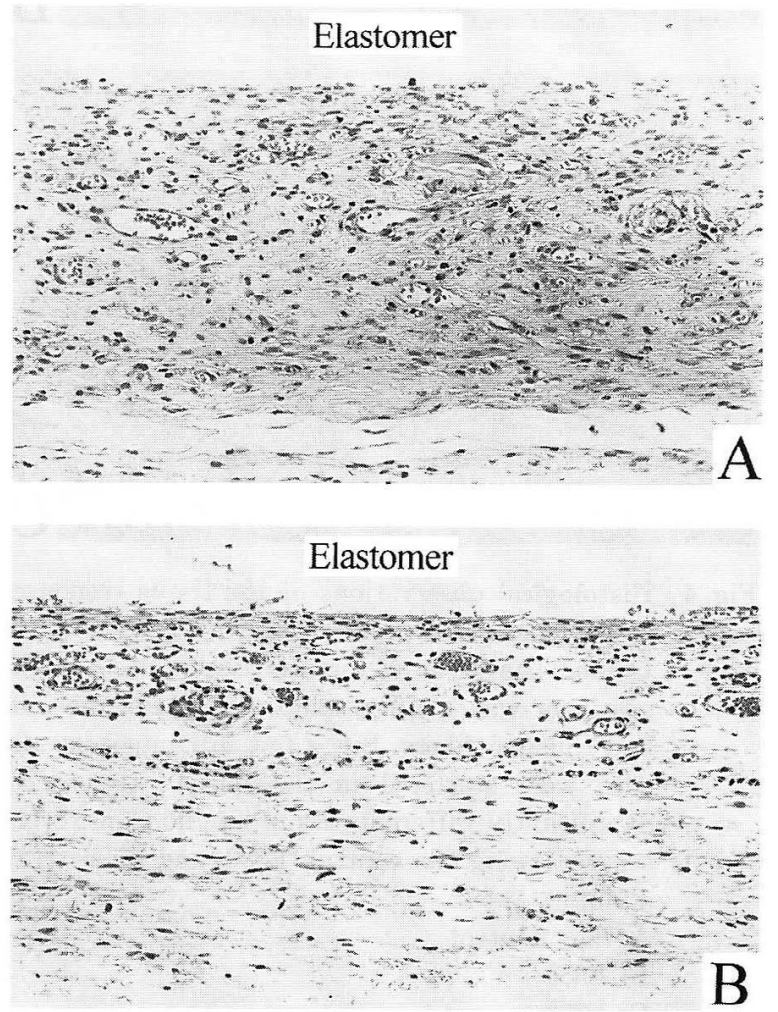

Fig. 3 Histological observations of the tissue responses of the specimens on the 7th day after implantation. Enlarged blood vessels and congestions accompanied with the inflammatory infiltration were observed (H.E. staining, $\times 50$ ).

A: The control

B: $\mathrm{E} 580$ 

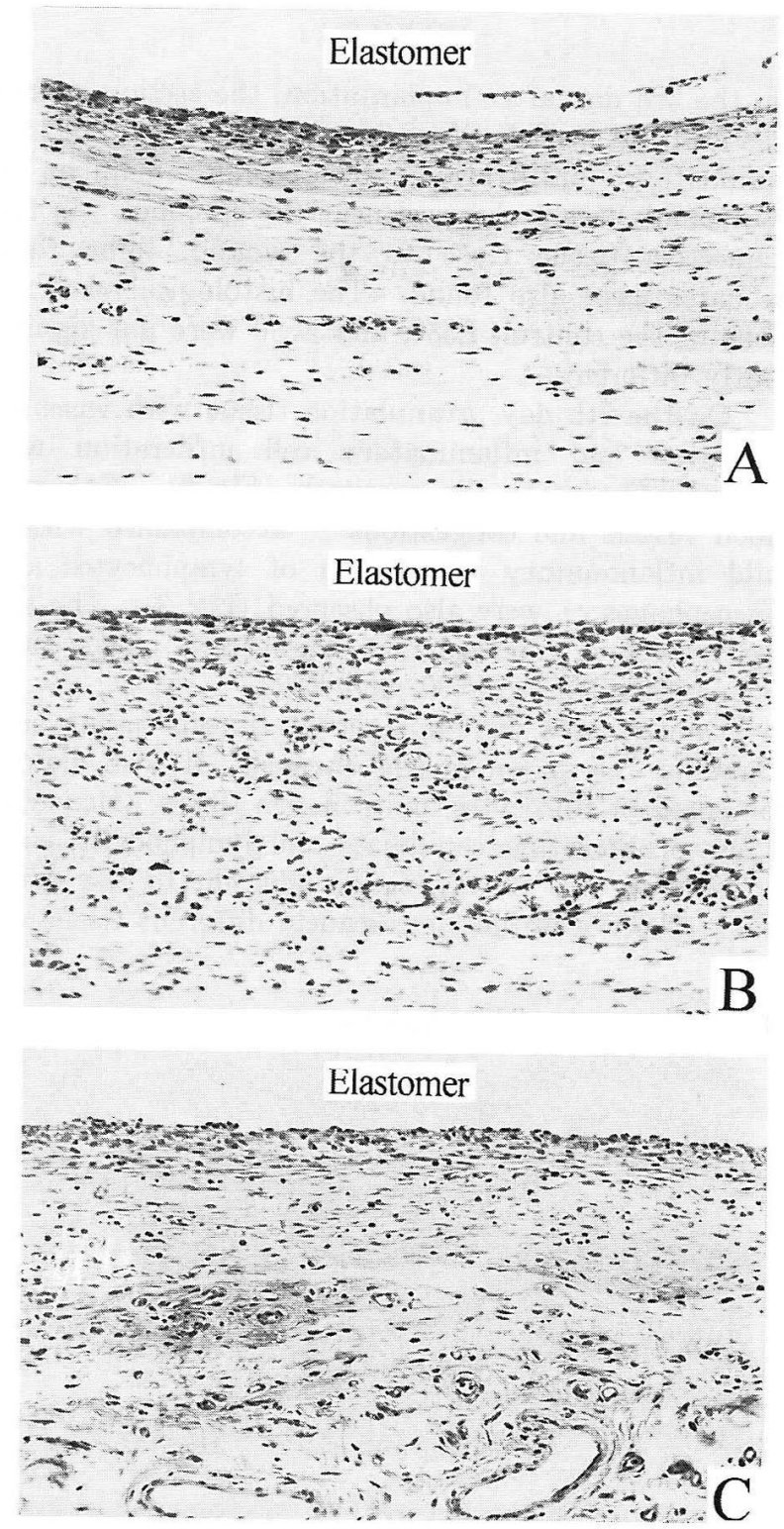

Fig. 4 Histological observations of the tissue responses of the specimens on the 14th day after implantation. The layer of fibrous tissue close to the specimen was mainly composed of fibrous cells and collagen fibers. But a few inflammatory tissues were scattered in the fibrous tissue. No significantly different tissue reactions were observed among the control, E580, and E590 (H.E. staining, $\times 50)$.
A: The control
B: $\mathrm{E} 580$
C: $\mathrm{E} 590$

actions among the control, E580, and E590 (Fig. 4).

On the 28th day, a fibrous capsule surrounding the specimen was observed. Fibrous cells were regularly arranged with the collagen fibers. Inflammatory cells and abnormal vessels were not found in the fibrous capsule.

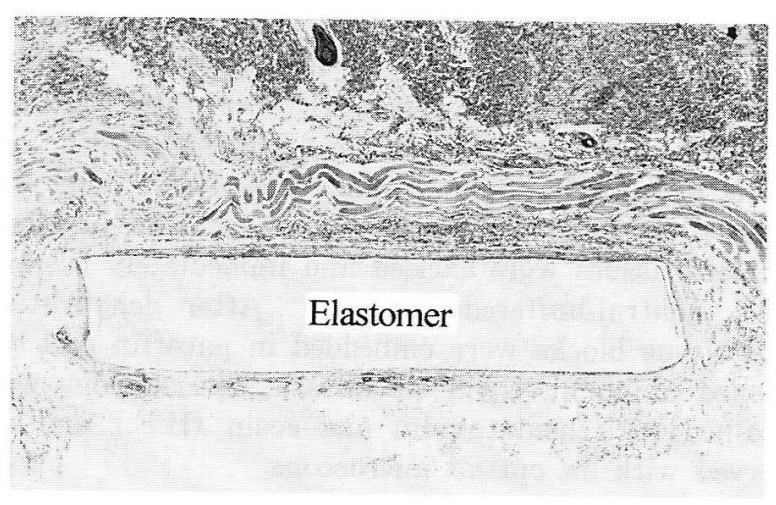

Fig. 5 Histological observation of the tissue response of the specimen (E590) on the 56th day after implantation. A thin, well-defined fibrous capsule surrounding the specimen was observed (H.E. staining, $\times 6.6)$.

On the 56th day, a well-defined fibrous capsule which composed of fibrocyte and collagen bundles was observed (Fig.5). The collagen fibers were much more in composition quantity than the cellular components. The fibrous tissue surrounding the specimen had become more stable than on the 28th day. There were no signs of any inflammatory cell or tissue. The observed tissue reactions showed no significant differences among the elastomers (Fig. 6).

\section{DISCUSSION}

Elastomers are divided into industrial- and medicalgrade elastomers according to the purity of the polymer. Extensive studies on the biocompatibility of medical-grade polyurethane elastomcrs have been reported $^{7-10)}$. The elastomers showed sufficient biocompatibility when implanted in the tissues. On this basis, the clinically used medical-grade elastomer was selected as the control. Its main component was the polyurethane elastomer. The experimental elastomers, E580 and E590, on the other hand are two kinds of industrial-grade elastomer. The crosslinks in their structures were different, but the composition was the same polyurethane polymer. Although the main component of the industrial-grade elastomer was similar to that of the medical-grade one, there might be some impure components in the former which could irritate the tissue. Therefore, the biocompatibility of the experimental elastomers should be investigated before they could be applied in clinical practice.

To evaluate a material's biocompatibility, various methods are available: cell culture ${ }^{11,12)}$, intramuscular implantation ${ }^{13)}$, subcutaneous implantation ${ }^{14-19)}$, and others ${ }^{20)}$. The subcutaneous implantation test is often used to evaluate tissue reaction for dental materials $^{21-23)}$. When a specimen is implanted into the 

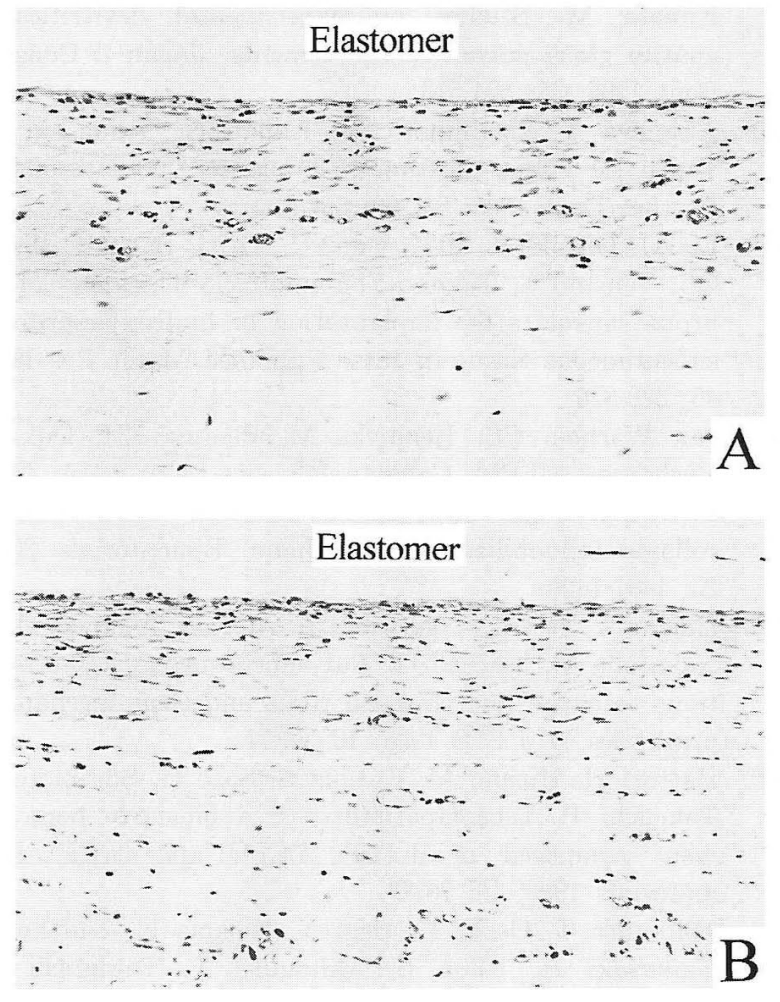

Elastomer-

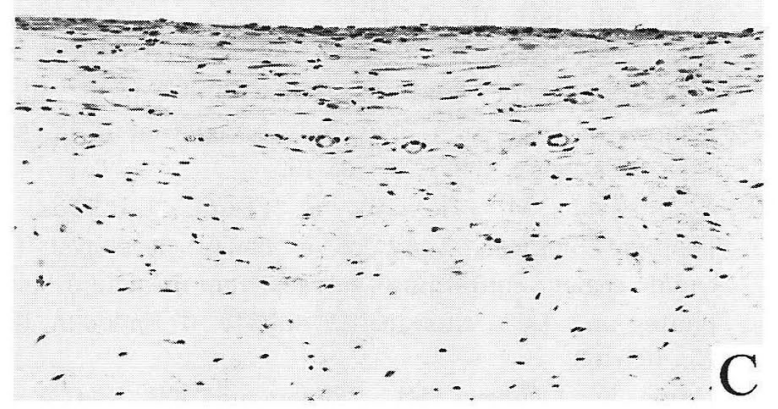

Fig. 6 Histological observations of the tissue responses of the specimens on the 56th day after implantation. The fibrous capsule, composed of thin connective tissue, was in a stable state. No different tissue reactions among the control, E580, and E590 were found (H.E. staining, $\times 50$ ).

A: the control

B: $\mathrm{E} 580$

C: E590

tissue, it will invoke a tissue reaction - the degree of which depends mainly on the irritation caused by the inserted specimen. However, physical properties such as shape and surface texture also influence the result ${ }^{18)}$. Therefore, in this study, all the specimens were of the same shape and size.

In general, the reaction begins as a surgical injury followed by a series of progressions including acute inflammation, chronic inflammation, foreign body reaction, and fibrosis or fibrous encapsulation $^{24)}$. In the present study, the wound was not completely healed after three days. Thus, it would be reasonable to regard the observed tissue response as operation influence. After one week, granulation tissue was formed around all the three kinds of elastomer. Indeed, inflammatory response due to the implanted elastomers was demonstrated early in the post-implantation period.

But after two weeks, the inflammatory reaction was on the decline. The inflammatory cells greatly diminished and fibrous tissue began to form near the specimen. At the end of 4 th week, all the specimens were encapsulated by fibrous cells and fibers. In other words, the interaction between tissue and specimen had reached a relatively stable state. After eight weeks, only the fibrous encapsulation existed between the tissue and specimen for all the elastomers. The specimen was encapsulated as longterm, foreign body in the subcutaneous tissue. Moreover, the tissue responses of the experimental elastomers, E580 and E590, were found to be similar to that of the clinically used elastomer. The reason was not clear, but it might be that the impure components in the experimental elastomers was of low quantity or had little irritation to the tissue inherently.

\section{CONCLUSION}

In the present study, the biocompatibility of both the experimental and clinically used elastomers was evaluated by a subcutaneous implantation test under the same conditions. A longitudinal histological examination was done, and it was found that the longterm, subcutaneous tissue irritation of the experimental elastomers, E580 and E590, was low. On this basis, we concluded that the experimental elastomers have the potential to be used clinically.

\section{ACKNOWLEDGEMENTS}

The authors would like to thank Dr. K. Higa and Dr. Y. Xia, Division of Pediatric Dentistry, Department of Oral Growth \& Development, for heartily aiding in the experiment. We are also very grateful to Dr. B. Sawakuma, Division of Pathology, Department of Morphological Biology, and Mr. K. Morishita, Department of Morphological Biology, for providing the much valued assistance and advice.

\section{REFERENCES}

1) Itoh Y. The study of fluoride-releasing rubber for separation of teeth. Jpn J Ped Dent 2000; 38: 562-575.

2) Wang XY. Study on the fluoride-releasing polyurethane elastomers in orthodontics - The mechanical properties and enhancement of acid resistance. $J$ 
Fukuoka Dent Coll 2004; 31: 21-32.

3) Lin DT, Young TH, Fang Y. Studies on the effect of surface properties on the biocompatibility of polyurethane membranes. Biomaterials 2001; 22(12): 1521-1529.

4) Saad B, Hirt TD, Welti M, Uhlschmid GK, Neuenschwander P, Suter UW. Development of degradable polyesterurethanes for medical applications: in vitro and in vivo evaluations. J Biomed Mater Res 1997; 36: 65-74.

5) Buruiana T, Spridon D, Buruiana EC, Hefco V, Uglea CV. Polyurethanes based on dihydroxamic acids: Synthesis, chemical characterization and biological activity. J Biomater Sci Polym Ed 1999; 10: 1159-1170.

6) Jeschke MG, Hermanutz V, Wolf SE, Koveker GB. Polyurethane vascular prostheses decreases neointimal formation compared with expanded polytetrafluoroethylene. J Vasc Surg 1999; 29: 168-176.

7) Gonzalez JB. Polyurethane elastomers for facial prostheses. J Prosthet Dent 1978; 39: 179-187.

8) Pennisi VR. Long-term use of polyurethane breast prostheses: A 14-year experience. Plast Reconstr Surg 1990; 86: 368-371.

9) Behrend D, Schmitz KP. Polyurethane or silicone as long-term implant substance - A critical evaluation. Biomed Tech (Berl) 1993; 38: 172-178.

10) Pavlova M, Draganova M. Biocompatible and biodegradable polyurethane polymers. Biomaterials 1993; 14: 1024-1029.

11) Locci $P$, Marinucci L, Lilli C, Belcastro S, Staffolani N, Bellocchio S, Damiani F, Becchetti E. Biocompatibility of alloy used in orthodontics evaluated by cell culture tests. J Biomed Mater Res 2000; 51: 561-568.

12) Kumazawa R, Watari F, Totsuka Y. Size dependence of vital reaction against minute particles of titanium in vivo and in vitro. J J Dent Mater 2001; 20: 356-365.

13) Christ FR, Buchen SY, Fencil DA, Knight PM. A comparative evaluation of the biostability of a poly (ether urethane) in the intraocular, intramuscular and subcutaneous environments. J Biomed Mater Res 1992; 26: 607-629.

14) Okada T, Ikada YJ. Tissue reactions to subcutaneously implanted, surface-modified silicones. Biomed Mater Res 1993; 27: 1509-1518.

15) Sasaki H, Oyama M, Kumagai H, Kudou Y, Takeda Y,
Kubota M. Studies on experimental devitrificated apatite glass polyalkenoate cements. Japan J Conserv Dent 1995; 38: 504-513.

16) Akigawa $Y$, Hashimoto $M$, Kondo $N$, Yamasaki A, Tsuru H. Tissue reaction to implanted biomaterials. J Prothet Dent 1985; 53: 681-686.

17) Li DJ, Ohsaki K, Ii K, Cui PC, Ye Q, Baba K, Wang $\mathrm{QC}$, Tenshin S, Takano-Yamamoto T. Thickness of fibrous capsule after implantation of hydroxyapatite in subcutaneous tissue in rats. J Biomed Mater Res 1999; 45: $322-326$.

18) van Wachem PB, Hendriks M, Blaauw EH, Dijk F, Verhoeven MLPM, Cahalan PT, van Luyn MJA. Electron microscopic observations on tissue integration of collagen-immobilized polyurethane. Biomaterials 2002; 23: 1401-1409.

19) Hidaka $Y$, Ito $M$, Yokoyama $K$, Mori K, Yamakura K, Nakajima M, Igarashi T. Rat subcutaneous tissue reactions to chitin and chitosan films and their mechanical properties. J J S B 1998; 16: 66-71.

20) Hattori H, Hirano M, Katuda S, Sato H, Sugimoto S, Takeuchi H. Biocompatibility of a bioactive bone cement composed of a-TCP, DCPD and TeCP. Biomaterials 1998; 16: 78-87.

21) Matsuura $T$, Osaki H, Hegi $Y$, Hisama K, Tanaka T, Yamasaki H, Ukon S, Matsuura T, Taniguchi K, Matsuo H, Ogawa M, Kitamura K. Histopathological study of rat connective tissue response to photopolymerized crown and bridge resin. J Fukuoka Dent Coll 1994; 21: 25-34.

22) Bilginer S, Esener IT, Soylemezoglu F, Tiftik AM. The investigation of biocompatibility and apical microleakage of tricalcium phosphate based root canal sealers. J Endodon 1997; 23: 105-109.

23) Yoshikawa M, Hayami S, Tsuji I, Toda T. Histopathological study of a newly developed root canal sealer containing tetracalcium-dicalcium phosphates and $1.0 \%$ chondroitin sulfate. J Endodon 1997; 23: $162-166$.

24) Udipi K, Ornberg RL, Thurmond KB, Settle SL, Forster D, Riley D. Modification of inflammatory response to implanted biomedical materials in vivo by surface bound superoxide dismutase mimics. J Biomed Mater Res 2000; 51: 549-560. 